\title{
Effects of Mechanical Stress Stimulation on Function and Expression Mechanism of Osteoblasts
}

\author{
Pan $\mathrm{Liu}^{1,2+}$, Ji Tu${ }^{3 \dagger}$, Wenzhao Wang ${ }^{4}$, Zheng $\mathrm{Li}^{5}$, Yao $\mathrm{Li}^{1,2}$, Xiaoping $\mathrm{Yu}^{6,7 *}$ and \\ Zhengdong Zhang ${ }^{1,2,8 *}$
}

${ }^{1}$ School of Clinical Medicine, Chengdu Medical College, Chengdu, China, ${ }^{2}$ The First Affiliated Hospital of Chengdu Medical College, Chengdu, China, ${ }^{3}$ Spine Labs, St. George \& Sutherland Clinical School, University of New South Wales, Sydney, NSW, Australia, ${ }^{4}$ Department of Orthopedics, West China Hospital of Sichuan University, Chengdu, China, ${ }^{5}$ People's Hospital of Jiulongpo District, Chongqing, China, ${ }^{6}$ School of Public Health, Chengdu Medical College, Chengdu, China, ${ }^{7}$ Basic Medical College of Chengdu University, Chengdu, China, ${ }^{8}$ Department of Orthopedics, The First Affiliated Hospital of Chengdu Medical College, Chengdu, China

OPEN ACCESS

Edited by:

Yun Qian,

Shanghai Jiao Tong University, China

Reviewed by:

Christian Hellmich,

Vienna University of Technology,

Austria

Chuandong Wang,

Shanghai Jiaotong University, China

*Correspondence:

Xiaoping $Y u$

cyggwsyxp@sina.com

Zhengdong Zhang

doctorzzd@vip.qq.com

${ }^{t}$ These authors have contributed equally to this work and share first

authorship

Specialty section:

This article was submitted to

Biomaterials,

a section of the journal Frontiers in Bioengineering and

Biotechnology

Received: 07 December 2021

Accepted: 10 January 2022

Published: 17 February 2022

Citation:

Liu P, Tu J, Wang W, Li Z, Li Y, Yu X and Zhang $Z$ (2022) Effects of Mechanical Stress Stimulation on Function and Expression Mechanism of Osteoblasts.

Front. Bioeng. Biotechnol. 10:830722. doi: 10.3389/fbioe.2022.830722
Osteoclasts and osteoblasts play a major role in bone tissue homeostasis. The homeostasis and integrity of bone tissue are maintained by ensuring a balance between osteoclastic and osteogenic activities. The remodeling of bone tissue is a continuous ongoing process. Osteoclasts mainly play a role in bone resorption, whereas osteoblasts are mainly involved in bone remodeling processes, such as bone cell formation, mineralization, and secretion. These cell types balance and restrict each other to maintain bone tissue metabolism. Bone tissue is very sensitive to mechanical stress stimulation. Unloading and loading of mechanical stress are closely related to the differentiation and formation of osteoclasts and bone resorption function as well as the differentiation and formation of osteoblasts and bone formation function. Consequently, mechanical stress exerts an important influence on the bone microenvironment and bone metabolism. This review focuses on the effects of different forms of mechanical stress stimulation (including gravity, continuously compressive pressure, tensile strain, and fluid shear stress) on osteoclast and osteoblast function and expression mechanism. This article highlights the involvement of osteoclasts and osteoblasts in activating different mechanical transduction pathways and reports changings in their differentiation, formation, and functional mechanism induced by the application of different types of mechanical stress to bone tissue. This review could provide new ideas for further microscopic studies of bone health, disease, and tissue damage reconstruction.

Keywords: mechanical stress, stimulation, function, expression mechanism, osteoblasts

\section{INTRODUCTION}

Mechanical forces affect almost every sphere of various life processes of living organisms, such as the perception of external hearing and touch, fluid flow and deformation during embryonic development, changes in cell osmotic pressure, pressure on blood vessel walls, and the movement of individual animals regulated by the earth's gravitational environment. These forces range from mechanical stress signal generation, induction, and transduction to the final response, which involves the cell membrane, cytoderm, cytoskeleton, and other structures. 
Bone tissue is very sensitive to mechanical stress stimulation. Unloading and loading of mechanical stress are closely involved in the differentiation and formation of osteoclasts and osteoblasts, and their bone resorption and formation functions, respectively (Robling and Turner, 2009; Li et al., 2020a). Consequently, mechanical stress exerts an important influence on the bone microenvironment and metabolism. Wolff's Law points out that the lack of mechanical stress would lead to bone microstructure degeneration, mass loss and metabolism disorders, and would ultimately lead to osteoporosis (Brand, 2010). The absence of mechanical stress, such as with limb casts fixation, bed-rest, reduced exercise, and the weightlessness of astronauts in space, can lead to significant bone loss (Berg et al., 2007; Ragnarsson, 2015). In contrast, the mechanical load caused by exercise can restore bone mass and reverse these effects in most situations (Iura et al., 2015; Suniaga et al., 2018).

Exposure of tissues and cells to external mechanical stress transforms the external mechanical force into local mechanical signals in the body, triggering responses of cellular sensors. Subsequently, cellular mechanical signals are coupled to biochemical signaling molecules such as the nitric oxide produced and prostaglandins (PGs) (Duncan and Turner, 1995; Johnson et al., 1996; Klein-Nulend et al., 1997). Osteoblasts, osteocytes, bone lining cells, osteoclasts, and macrophages can sense mechanical stimulation and respond directly or indirectly (Dong et al., 2021). Mechanical transduction in bone tissue cells is a complex but precise regulatory process between cells and the microenvironment, between adjacent cells, and between mechanical sensors with different functions in a single cell. Ion channels, integrins, gap junction proteins, focal adhesion kinase, the extracellular matrix, the cellular skeletal components (such as intermediate filaments, microtubules, and actin filaments), and primary cilia are mechanical sensors that have been proven to regulate intracellular signaling pathways (Qin et al., 2020).

In vitro studies often use peripheral blood mononuclear cells, monocyte cells, bone marrow derived precursors and RAW264.7 cells induced to exhibit osteoclast formation (Owen and Reilly, 2018; Xiang et al., 2020). Bone mesenchymal stem cells (BMSCs), Human periodontal ligament cells (hPDLCs) and mouse embryo osteoblast precursor (MC3T3-E1) cells were induced to form osteoblasts (Rutkovskiy et al., 2016). The metabolic characteristics and mechanism of bone formation and remodeling have been explored by observing and studying the process of bone differentiation and formation. Osteocytes, osteoclasts and osteoblasts play major roles in bone tissue homeostasis. Bone tissue remodeling is a continuous process in which the role of osteoclasts is mainly in bone resorption, whereas that of osteoblasts is mainly bone remodeling, such as bone cell formation, mineralization, and secretion (Hardy and Fernandez-Patron, 2020). RANKL secreted by osteocytes binds to the receptor RANK on the precursor surface of osteoclasts to promote the differentiation and maturation of osteoclasts. Osteocytes also secrete OPG, which acts as the decoy receptor of RANKL and negatively regulates RANK signal to prevent osteoclast differentiation. When the ratio of RANKL/OPG increases, bone resorption increases; when the ratio of
RANKL/OPG decreases, bone formation increases. In addition, osteocytes secrete sclerotin, which is a negative regulator of bone formation (Bonucci, 2009; Prideaux et al., 2016). These cell types balance and restrict each other to maintain bone tissue metabolism and homeostasis.

Previous studies have shown that appropriate mechanical stress stimulation can reduce the number and activity of osteoclasts and inhibit bone resorption, promote the differentiation and osteogenic function of osteoblasts, inhibit the differentiation of BMSCs into adipocytes, and prevent the loss of bone mass (Uzbekov et al., 2012). This effect also critically influences the regulation of bone metabolism signaling pathways (Uzbekov et al., 2012; Kameyama et al., 2013). However, the exact mechanism is not entirely clear. Numerous studies have further investigated the mechanism underlying the effects of mechanical stress on bone metabolism by examining mechanical stress stimulation in osteoclasts and osteoblasts (involving different species such as humans, mice and zebrafish,etc.) (Nomura and Takano-Yamamoto, 2000; Ho et al., 2005; Wittkowske et al., 2016). In this review, we review the mechanisms of mechanical stress stimulation on the function and expression of osteoblasts. Through this review, we attempt to provide a theoretical basis for the microscopic study of bone health, diseases, and injury reconstruction.

\section{MECHANORECEPTOR}

\subsection{Ion Channels}

Appropriate mechanical stimulation can activate calcium channels on the cell membrane to promote the transport of extracellular calcium into the cell, increasing the intracellular calcium concentration and promoting bone mass increase. Piezo1 and Piezo2 have been identified as important mechanosensitive channels. Piezo1 is a mechanosensitive ion channel through which osteoblasts sense and respond to changes in mechanical load and are required for gene expression changes caused by fluid shear stress (FSS) (Li et al., 2019; Zhou et al., 2020). Piezo1 expression in osteoblasts may also be promoted by mechanical tensile force (Wang et al., 2020a) and its deficiency in osteoblasts promotes bone resorption and contributes to osteoporosis in mice, but does not affect bone mass (Wang et al., 2020b).

Li et al. (Li et al., 2019) reported that the removal of Piezo1 from osteoblasts and bone cells does not completely eliminate the response of bones to mechanical stimuli. Furthermore, Piezol is not the only mechanosensor in osteoblasts and bone cells. Although Piezo1 and Piezo2 mRNA expression was detected in bone tissues, Piezol expression was significantly higher in bone cells and osteoblasts than that of Piezo2 (Sugisawa et al., 2020). Piezo2 is more involved in the development of the nervous system and the perception of touch and pain, than Piezo 1 is, including through molecules such as Merkel cells, outer hair cells and somatosensory ganglia (Woo et al., 2014). Other channels, such as the transient receptor potential (TRP) vanilloid (TRPV) and certain members of the epithelial $\mathrm{Na}^{+}$channel $(\mathrm{ENaC})$ protein family, can guide cation influx under a hypertonic environment or membrane tension, converting mechanical force signals into 
electrical and chemical signals (Gu and Gu, 2014; Kefauver et al., 2020).

\subsection{Cytoskeleton}

The cytoskeleton is a network structure in cells that is mainly composed of protein fiber (Kounakis and Tavernarakis, 2019), and mainly consists of microtubules, actin fibers, and intermediate filaments (Sandbo et al., 2016). It plays an important role in maintaining cell morphology, bearing external forces, and maintaining the internal cellular structure. The cytoskeletal structure is highly nonlinear, enabling cells to sense deformation and change and the complete cytoskeleton contributes to maintaining tight adhesion between cells and the extracellular matrix (ECM). The integrin glycoprotein family located on the cell membrane senses mechanical signals through interactions between the ECM and intracellular signals (Aisha et al., 2015). Human MSCs (hMSCs) can be gradually remodeled through cell recombination and arrangement and the regulation of smooth muscle cells by the cytoskeleton (Parandakh et al., 2017). Microtubule actin crosslinking factor 1 (MACF1) is a regulator of cytoskeletal dynamics that is necessary for maintaining bone tissue integrity (Wang et al., 2021a), whereas actin in the cytoskeleton is mainly involved in mechanical stress (Zhou et al., 2018). The link between mechanical stimulation, integrin/cytoskeleton/Scr/extracellular signal-regulated protein kinase (ERK) signaling pathway activation, and osteocyte survival provides a mechanical basis for the role of mechanical forces in the bone (Plotkin et al., 2005).

\subsection{Integrin}

Integrins are heterodimers formed by the non-covalent binding of $\alpha$ and $\beta$ subunits and presently, mammals are known to express18 $\alpha$ and $8 \beta$ subunits, which combine to form 24 integrins (Selvakumarasamy et al., 2019). Integrin senses physical or biochemical stimulation of the ECM by binding to its ligands (including fibonectin, collagen, and laminin) in the extracellular region. Furthermore, through conformational changes, integrin mediates the transmission of signals to cells to induce their adhesion, migration, proliferation, and differentiation. Moreover, intracellular signal changes also affect the conformational changes of integrin, alter the affinity of ligand binding, and affect the biological behavior of cells. This integrin-dependent bidirectional signal transduction mechanism plays an important role in bone remodeling (Uda et al., 2017; Kong et al., 2020; Michael and Parsons, 2020). Recent studies have shown that osteoclasts express integrin $\alpha 2$ and $\alpha \mathrm{V}$ and play an important role in bone resorption (Kong et al., 2020). Subsequent studies should focus on further clarifying the important role of integrin in mechanical stimulation and bone metabolism.

\subsection{Primary Cilia}

Primary cilia is widely found in osteocytes, MC3T3-E1 cells, murine long bone osteocyte-Y4 (MLO-Y4) osteoid cells, cranial osteoblasts, and hMSCs, and it is an important mechanoreceptor that responds to mechanical stimulation and coordinated load induction in these cells (Xiao et al., 2006; Malone et al., 2007;
Hoey et al., 2012). However, the existence of primary cilia in osteoclasts has not been reported in existing studies (Yuan et al., 2015). The exposure of osteoblasts and hMSCs to suitable FSS upregulated the expression levels of runt-related transcription factor 2 (RUNX2), bone morphogenetic protein 2 (BMP2), alkaline phosphatase (ALP), and osteopontin (Sonam et al., 2016). In bone cells, primary cilia act as mechanosensors that respond to and flex extracellular fluid impulses generated by the body during walking and running. When primary cilia bend, the increased tension on the membrane opens mechanosensitive ion channels, which leads to intracellular $\mathrm{Ca}^{2+}$ influx, membrane depolarization, and activation of nerve fibers and then, the cell experiences mechanical stimulation (Whitfield, 2003). Studies have shown that a simulated microgravity environment eliminates the formation of primary cilia, inhibits the formation and mineralization of rat skull osteoblasts, and significantly shortens the residual cilia (Shi et al., 2020). However, the specific mechanism underlying the action of primary cilia in the bone under mechanical stress has cannot be fully explained by current studies, and further elucidation is needed in future studies.

\section{MECHANICAL STIMULATION WITH OSTEOBLASTS}

\subsection{Gravity}

The force through which objects are attracted to each other on earth is called gravity, which is exerted by the earth, and the direction of gravity is always straight down.

\subsubsection{Hypergravity and Osteoblasts}

MC3T3-E1 cells as osteoblast precursors are commonly used for mechanical sensing and gravity studies, which often use different methods or stimulatory interventions to observe the effects of osteoblast differentiation. Hypergravity (a force of 5, 10, 20, and $40 \times \mathrm{g}$ ) was shown to promote the proliferation of MC3T3-E1 and osteoblast-like cells through a PGE2-mediated mechanism in vitro (Miwa et al., 1991), increase ALP activity, and was positively correlated with the duration of hypergravity (Nakajima, 1991). Similarly, hypergravity of $3 \times \mathrm{g}$ stimulates bone formation by enhancing the activity of osteopontin and RUNX2 in osteoblasts (Zhou et al., 2015). Kawao et al. (Kawao et al., 2020) found increased mRNA levels of RUNX2, osterix, ALP, and osteocalcin; ALP activity; and mineralization in vivo in osteoblasts from mice exposed to $3 \times \mathrm{g}$ hypergravity. In addition, Woodcock et al. (Woodcock et al., 2019) found that high gravity effectively increased the intracellular viscosity of MC3T3-E1 cells and promoted the maturation and differentiation of osteoblasts, whereas higher levels $(10,15$, and $20 \times \mathrm{g})$ had a more significant effect.

\subsubsection{Microgravity}

The force of gravity in space is one millionth that on earth $(9.8 \mathrm{~m} /$ $\mathrm{s}^{2}$ ). Microgravity can lead to osteoblast and osteoclast interaction disorders, resulting in bone loss, muscle relaxation, and the development of osteoporosis. Space microgravity and 
simulated microgravity (such as in plaster splintage, tail suspension test, sciatic denervation, and hindlimb unloading are commonly used in studies of bone metabolism in vivo and in vitro (Globus and Morey-Holton, 2016).

\subsubsection{Microgravity and Osteoblasts}

In space microgravity and simulated microgravity, sclerostin (SOST) enhances osteoclast formation by decreasing the production of osteoprotegerin (OPG) in osteoblasts and increasing the secretion of receptor activator of nuclear factor (NF)- $\kappa$ B ligand (RANKL) (Saxena et al., 2011; Chatani et al., 2016). Similar studies have shown that microgravity reduced osteoblast production and enhanced that of osteoclasts by decreasing OPG secretion by osteoblasts (increasing the RANKL/OPG ratio) (Rucci et al., 2007). Serum glucocorticoid levels increased significantly on day 3 in an animal model of hindlimb unloading that simulated microgravity. High glucocorticoid levels inhibited the expression of $\mathrm{Wnt} / \beta$-catenin signaling pathway molecules and upregulated the expression of SOST in bone cells (Yang et al., 2020). Therefore, enhanced secretion of glucocorticoid may be an important factor for bone loss in the hindlimb unloading model (Yang et al., 2020). A recent study showed that the leukemia inhibitory factor (LIF) enhanced signal transducer and activator of transcription 3 (STAT3) phosphorylation in BMSCs and increased the expression of ALP and osteogenic genes. However, in the in vitro microgravity environment, the secretion of LIF by bone cells was inhibited, which weakened the osteogenic effect (Du et al., 2020). Microgravity also increases the level of oxidative damage markers in the body and weakens the total antioxidant capacity.

Reactive oxygen species (ROS) inhibit the function of osteoblasts (Manolagas, 2010; Steller et al., 2018), promote MC3T3-E1 cell apoptosis, and downregulate the expression of MAF BZIP transcription factor G (MafG) (Wang et al., 2021b). Therefore, increased ROS expression in microgravity is also one of the key factors for bone loss. In addition, microRNA (miR)-494 inhibits BMP2-induced osteoblast differentiation by downregulating BMPR2 and RUNX2 under microgravity simulation (Qin et al., 2019). An increasing number of studies have shown that the inhibition of osteogenic differentiation in microgravity can be regulated by multiple non-coding RNAs (ncRNAs) (Wang et al., 2018; Wang et al., 2020c; Cao et al., 2021).

Although resistance training for astronauts can effectively prevent bone loss (Stein, 2013), the adverse effects of the space microgravity environment on the bones of astronauts can last for several years, which highlights the importance of studying bone metabolism under microgravity conditions. The huge cost of in vivo and in vitro experiments on space flight has necessitated the development of a variety of experimental platforms to simulate ground microgravity environments (Bonnefoy et al., 2021; Iordachescu et al., 2021). However, fully replicating the changes induced by space microgravity exposure is challenging and, therefore, the develop of more reliable and accurate ground microgravity simulation environments for in-depth research is necessary.

\subsubsection{Continuously Applied Compressive Pressure}

The force perpendicular to the surface of a fluid per unit area is called the static pressure of the fluid, and continuous action for a specified period of time is called the continuously applied compressive pressure (CCP) (Xing et al., 2004). As a form of stress stimulated by mechanical stress, CCP is an effective condition for stimulating bone tissue growth. However, when CCP is too high or insufficient, it can reduce bone mass and lead to bone loss.

\subsubsection{Continuously Applied Compressive Pressure and Osteoblasts}

Imamura et al. (Imamura et al., 1990) Found that CCP inhibits osteoblast differentiation of MC3T3-E1 cells through production of PGE2. Their further study found that applying continuous static pressure (3 atm, ATM) to MC3T3-E1 cells inhibited the ALP activity of the osteoblasts and promoted PGE2 secretion. When MC3T3-E1 cells were transferred to a $\mathrm{CO}_{2}$ incubator at 1 ATM, the inhibition of ALP activity was rapidly reversed (Ozawa et al., 1990). Yanagisawa et al. (Yanagisawa et al., 2008) reported that $1.0 \mathrm{~g} / \mathrm{cm}^{2}$ compressive stress was the optimal condition for osteoblast differentiation, and the study by Tripuwabhrut et al. (Tripuwabhrut et al., 2013) showed that osteoblast differentiation was enhanced when compressive stress increased from $2.0 \mathrm{~g} / \mathrm{cm}^{2}$ to $4.0 \mathrm{~g} / \mathrm{cm}^{2}$. Xiaoqing Shen et al. (Shen et al., 2017) showed that compressive stress at the range of $5.0 \mathrm{~g} / \mathrm{cm}^{2}$ had no significantly different effects on the survival rate of MC3T3-E1 cells.

These results indicate that CCP has a positive effect on the differentiation of MC3T3-E1 cells and osteoblasts, but the exact dose of CCP for MC3T3-E1 cells and specific effects are currently unclear. Recently, Shu et al. (Somemura et al., 2021) reported that treating osteoblasts in a three-dimensional (3D) cell-collagen sponge construct with $25.5 \mathrm{gf} / \mathrm{cm}^{2}(2.5 \mathrm{kPa})$ for $24 \mathrm{~h}$ upregulated glucose transporter1 (Glut1), RUNX2 and ALP, whereas silent mating type information regulation 2 homolog 1 (sirtuin 1, SIRT1) was downregulated in osteoblasts induced by compressive mechanical loading. They hypothesized that the Glut1/SIRT1/RUNX2 pathway in osteoblasts may play a role in mechanical stress-induced bone formation and osteoblast differentiation. In vitro studies have repeatedly confirmed that osteocytes (not only osteoblasts, but also osteoblasts, osteoclasts and their progenitors) do indeed exhibit altered activity at hydrostatic pressures of up to $1 \mathrm{~Hz}$, with amplitudes of tens (to hundreds) of kilopascals. Since in-situ tests are somewhat difficult to achieve, Whether hydrostatic pressure, identified in vitro as mechanical stimulation, actually occurs in vivo is controversial (Duncan and Turner, 1995). With this problem in mind, the multi-scale mechanical biology method and multi-scale mechanical model proposed by Scheiner et al. that connect porous micromechanics and mathematical systems biology provide valuable insights for this problem (Scheiner et al., 2014; Scheiner et al., 2016; Estermann and Scheiner, 2018). In addition, reports of CCP on osteoblast differentiation and osteoclast differentiation regulated by osteoblasts are still being explored (Tripuwabhrut et al., 2013). The effects of CCP strength 
and duration on osteoblasts will be precisely defined in future studies.

\subsubsection{Tensile Strain}

Various types of stress can produce relative strain when applied to an object. The ratio of the length, shape, and volume variation of the object before and after the action of tensile stress (single/ bidirectional tensile stress) is called tensile strain. Ilizarov (Ilizarov, 1989) was the first to successfully apply traction stress to stimulate bone formation, and proposed the theory of "distraction osteogenesis". To date, the theory has been successfully applied in strategies for the repair and treatment of bone defects (Kani et al., 2020).

\subsubsection{Tensile Strain and Osteoblasts}

The tensile stress of osteoblasts cultured in vitro was mainly achieved by stretching the culture medium membrane that adhered to the osteoblasts. In applying stretch stress to the culture medium membrane, the strength and duration can be controlled to observe the different responses of osteoblasts to stretch tension under different conditions. Furthermore, this process passively pulls osteoblasts that have adhered to the culture medium membrane, which simulates osteoblast stress in vivo. Chen et al. (Chen et al., 2018) found that mechanical stretching of human jaw bone marrow MSCs using the Flexcell tension system in vitro significantly increased ALP activity and calcium deposition. Moreover, the expression levels of RUNX2 and osterix were significantly upregulated, whereas NF-KB was significantly downregulated. Davidson et al. (Davidson et al., 2013) performed a mandibular osteotomy and pull experiment on Sprague-Dawley rats using a pull osteogenesis technique. The results showed that BMP2, intranuclear SMAD family member 1 (SMAD1) phosphorylation and ALP activity were increased in the traction region, and the osteogenic effect was significantly increased. Wnt1 expression was found to be elevated in alveolar bone cells on the tension side of orthodontic tooth movement (OTM) mouse model for 5 days (Ei Hsu Hlaing et al., 2020).

In addition to mechanical tensile force acting directly on osteoblast precursors and osteoblasts, it can also induce osteogenesis indirectly by affecting other mechanosensitive cells. Dong et al. (Dong et al., 2021) reported that macrophages are exposed to cyclic stretching with a 5\% strain at a frequency of $1.0 \mathrm{~Hz}$ for up to $12 \mathrm{~h}$ using the FX-4000 Flexcell, and the stretched macrophages were co-cultured with BMSCs. The expression of opsin (OPN) and RUNX2 was significantly increased and induced Yes-associated protein (YAP) activation and nuclear translocation, which subsequently regulated downstream BMP2 expression to promote BMSCs osteogenesis (Dong et al., 2021). Li et al.(2020b) induced distraction osteogenesis of osteoblasts, and found that their proliferation was enhanced and mRNA levels of ALP, RUNX2, osteocalcin (OCN), collagen type I, hypoxia-inducible factor (HIF)- $1 \alpha$ and vascular endothelial growth factor (VEGF) were significantly increased.

However, in vivo studies showed that locally generated bacterial inflammation inhibited RUNX2 expression and upregulated $\mathrm{c}$-fos and interleukin (IL)- $1 \beta$ expression levels in osteoblasts induced by tensile strain, and reduced the osteogenesis of osteoblasts under continuous tensile stress (Lacey et al., 2009; Li et al., 2021). Obesity induced by high-fat diet decreases osteoblast activity in alveolar bone of the OTM stretching side (Luo et al., 2021). Therefore, it is necessary to consider several factors to maximize the function of osteoblasts using tensile stress.

\subsubsection{Fluid Shear Stress}

Fluid shear stress (FSS) is a type of mechanical stress caused by extracellular fluid, such as tissue fluid, flowing through the cell membrane surface, and the theory that FSS is induced by the flow of tissue fluid in the lacunar-canalicular system is widely accepted (Kumar et al., 2021). Applying loads (including mechanical loads, muscle contractions, blood pressure, and lymphatic drainage) to the bones causes the interstitial fluid to flow, which compresses the lacunar-canalicular system, thereby inducing various mechanical stimuli including FSS (Duncan and Turner, 1995; Tanaka et al., 2005; Price et al., 2011). FSS can further induce changes in the biomechanical properties of osteoblasts.

\subsubsection{Fluid Shear Stress and Osteoblasts}

Previous studies have shown that FSS inhibits tumor necrosis factor (TNF)- $\alpha$-induced osteoblast apoptosis (Pavalko et al., 2003). More recent studies have shown that FSS can activate the ERK5-serine-threonine protein kinase B (AKT)-forkhead box O3a (FoxO3a)-Bim/FasL signaling pathway, inhibit the activation of caspase 3, and protect osteoblasts from apoptosis induced by TNF- $\alpha$ (Bin et al., 2016). Wang X. et al. (Wang et al., 2021e) found that the expression level of long-coding (RNA) lncRNA taurine up-regulated 1 (TUG1) increased in a time-dependent manner when MC3T3-E1 cells were exposed to $12 \mathrm{dyn} / \mathrm{cm}^{2}$ FSS treatment for 30, 60, and $90 \mathrm{~min}$. LncRNA TUG1 upregulated fibroblast growth factor receptor 1 (FGFR1) expression by sponging miR$34 \mathrm{a}$, which promoted osteoblast proliferation and inhibited osteoblast apoptosis (Wang et al., 2021e).

This study also found that FSS downregulated miR-140-5p and promote osteoblast proliferation by activating the vascular endothelial growth factor-A (VEGFA)/ERK5 signaling pathway (Wang et al., 2021d). FSS increased the expression of Piezol in MC3T3-E1 cells, activated the AKT- serine-threonine protein kinase glycogen synthase kinase 3 (GSK3)/ $\beta$-catenin pathway and upregulated the expression level of RUNX-2 (Song et al., 2020). FSS remodels the cytoskeleton of MC3T3-E1 cell; arranges F-actin proteins in one direction, making them more compact and uniform; and increases the expression level of phosphopaxillin and integrin- $\alpha 5$ (Jin et al., 2020).

Recently, the in-depth study of bone ingrowth between internal fixation materials and bone interface has encouraged the study of material-bone interface-mechanical stimulation as an emerging focus. Lei et al.(2021) reported the effect of FSS on human MG-63 osteoblast-like cells on titanium with different surface modifications, which was particularly evident on the implant-bone interface. This study found that FSS (12 dyn/ $\mathrm{cm}^{2}$ ) significantly induced cell proliferation and upregulated the expression level of focal adhesion kinase (FAK), which the authors speculated that FAK may play a key role in the 
mechanical transduction of the implant-bone interface (Lei et al., 2021).

FAK is a nonreceptor tyrosine kinase, which plays a key role in integrin-mediated signal transduction and downstream signaling pathways (Tapial Martinez et al., 2020). Wang J. et al. (Wang J. et al., 2021) found that the interface force or adsorption force of protein-material can regulate the organization of the actin cytoskeleton and promote the formation of focal adhesion, and that FSS promotes assembly of the actin cytoskeleton and decomposition of focal adhesions. These emerging studies will contribute to the designing of a harmonious bioreactor and mechanical load to facilitate the comprehensive study of bone tissue regeneration.

\section{SIGNAL PATHWAYS MEDIATING EFFECTS OF MECHANICAL STRESS STIMULATION ON OSTEOBLASTS}

Mechanical load induces stress stimulation of the bone and transmits the force to the bone cells. The receptors on the cell membrane are activated by binding of specific ligands, which triggers the signal cascade and enhances expression of downstream target genes, playing a role in bone metabolism. Mechanical transduction is a complex process regulated by multiple signal pathways.

\subsection{Wnt $/ \beta$-Catenin Signaling Pathway}

The Wnt/ $\beta$-catenin pathway is one of the most important pathways studied in bone metabolism research. Exposure of the transmembrane co-receptors low-density lipoprotein (LDL) receptor related protein 5 (Lrp5), Lrp6, and Frizzled (FZD) protein family to Wnt, activates the Lrp/FZD receptor complex on the cell surface, which inhibits the degradation activity of $\beta$-Catenin through the phosphorylation of downstream protein kinases. Subsequently, the stably accumulated $\beta$-catenin in the cytoplasm enters the nucleus and combines with the T-cell factor/lymphoid enhancer factor (TCF/LEF) transcription factor family to initiate the transcription of downstream target genes to promote the expression of osteogenic genes (such as $O P G$ ) and promote bone formation. Studies have found that mice with Lrp5 deletion mutations continue to show a state of low bone mass (Sawakami et al., 2006; Iwaniec et al., 2007).

More recent studies showed that human patients with Lrp5 missense mutation (A745V) had severe osteoporosis, which may be attributable to the weakening of the anabolic response of bones to mechanical stress (Kiel et al., 2007; Norwitz et al., 2019). Lrp5 and Lrp6 have been shown to be extremely important in bone cell mechanical transduction (Jing et al., 2016). In addition, under mechanical load, heterozygous deletion of $\beta$-catenin in a single osteocyte in mice eliminates the bone synthesis response to mechanical load and the ability to form new bone (Javaheri et al., 2014). Numerous studies using in vitro and in vitro models have also demonstrated the involvement of the Wnt pathway in mechanical stress (Bonewald and Johnson, 2008; Duan and Bonewald, 2016; Kang et al., 2016; Fu et al., 2020).
However, SOST negatively regulates the Wnt/ $\beta$-catenin pathway (Choi and Robling, 2021).

Dickkopf-related protein (DKK) 1 and DKK2 are expressed by osteocytes and negatively regulate $\mathrm{Wnt} / \beta$-catenin. The mechanical load can inhibit the expression of DKK1 in osteocytes and promote the upregulation of Wnt signaling (Holguin et al., 2016). In vivo studies using hypergravity $(3 \times$ g) showed significantly reduced DKK2 levels in the serum and DKK2 mRNA levels in the soleus muscle of mice (Kawao et al., 2020). DKK2 was shown to inhibit mRNA levels of RUNX2, osterix, ALP, and osteocalcin and alkaline phosphatase activity and mineralization in osteoblasts, and enhance the phosphorylation of $\beta$-catenin in mouse osteoblasts (Kawao et al., 2020). Regulation of the Wnt pathway has a positive effect on compensatory mechanisms for coping with mechanical stress and changing bone mass, but the specific mechanism remains to be further studied.

\subsection{Notch Signaling Pathway}

The Notch signaling pathway, which is expressed in almost all organ systems, is highly conserved and plays an important role in the occurrence and development of diseases by regulating various cell processes (Andersson et al., 2011). Mammals have multiple Notch receptors, and the common types are Notch 1, Notch 2, Notch 3, and Notch-4. The Notch receptor is a one-way transmembrane protein that consists of the Notch extracellular domain (NECD), Notch transmembrane domain (NTM), and Notch intracellular domain (NICD). In mammalian cells, members of the delta-like ligand (DLL1, DLL3, and DLL4) and Jagged (JAG1 and JAG2) families act as ligands for Notch signaling receptors (Steinbuck and Winandy, 2018). Binding of the specific ligand to the receptor activates the Notch signaling pathway and its downstream target genes [including hes family bHLH transcription factor 1 (Hes1), hes related family bHLH transcription factor with YRPW motif 1 (Hey1), and Hey2] are transcribed. It is worth mentioning that Hes1 is a key factor in bone metabolism (Zanotti et al., 2011).

The role of Notch receptors in bone metabolism has always been controversial. Overexpression of NICD1 in osteocytes reduces bone resorption, leading to an increase in bone mass. Conversely, specific activation of Notch signaling in immature osteoblasts impaired their differentiation, leading to osteopenia (Canalis et al., 2013). Wang L. et al. (Wang et al., 2020a) found that mechanical stretch stress can activate the Notch1 signaling pathway and the expression of ALP, RUNX2, OCN, bone sialoprotein (BSP), and promote the osteogenic differentiation of human periodontal ligament stem cells. Ziouti et al. (Ziouti et al., 2019) found that applying tibial cyclic compression load $(216$ cycles at $4 \mathrm{~Hz}$, peak strains at a tibial midshaft of $+900 \mu \varepsilon)$ to wild-type mice induced specific Notch target genes (mRNA expression of Hes1, Hey1, and Hey2). Cyclic stretching of primary human BMSCs increased the gene expression of Notch receptors Notch 1 and Notch 2 by more than 60 -fold and 30 -fold, respectively. RUNX2 and mechanical response genes prostaglandin-endoperoxide synthase 2 (PTGS2) and FOS were upregulated. Studies have shown that the Notch pathway is activated and osteogenic gene expression is upregulated in 
osteoblasts under mechanical stress. However, the exact mechanism of the Notch pathway-related effects in osteoblasts under mechanical stress has not been fully elucidated.

\subsection{ERK5 Signaling Pathway}

ERK, which belongs to the mitogen-activated protein kinases (MAPKs) family, has strong catalytic activity and plays a key role in upstream signal transduction pathways including mechanical signals in cellular reactions (Fey et al., 2012; Yuan et al., 2020). Studies have shown that loading MC3T3-E1 cells with FSS increases cyclooxygenase (COX)-2 activity, which activates osteoblast-like cell proliferation and anabolic metabolism (Bo et al., 2016; Ding et al., 2019). Knockout of ERK5 using small interfering RNA (siRNA) prevented FSS from upregulating COX2 and cyclic adenosine monophosphate (cAMP) (Jiang et al., 2015). Wang X. et al. found that FSS-induced downregulation of miR-140-5p regulates ERK5 signal activation through VEGFA and promotes osteoblast proliferation (Wang et al., 2021d). FSS inhibits caspase 3 activation to prevent osteoblast apoptosis by activating the ERK5-AKT-Foxo3a pathway in MC3T3-E1 cells (Bin et al., 2016). Other studies have shown that the effect of mechanical load on ERK5 is an important factor affecting the proliferation of osteoblasts (Li et al., 2012; Zhang et al., 2021).

\subsection{RhoA Signaling Pathway}

RhoA belongs to the Rho Family of small GTPases, and is a key regulator of actin cytoskeleton. The mammalian genome encodes about 20 kinds of Rho gtpase, and currently the most researched ones are RhoA, Racl and Cdc42 (Ridley and Hall, 1992). The activation and inactivation of RhoA is regulated by signals from intracellular and extracellular $G$ protein coupled receptors, integrins and growth factor receptors (Kaneko-Kawano and Suzuki, 2015). Members of the Rho associated protein kinase (ROCK) family, including ROCK1 and ROCK2, are important effectors of RhoA (Arnsdorf et al., 2009). When exogenous forces or forces generated by the cell itself and the cytoskeleton act on the cell (Chen, 2008), cell surface adhesions, cytoskeleton and membrane tension work together to affect mechanosensors and stimulate mechanical responses (Vogel and Sheetz, 2006; Hoffman et al., 2011). Studies have shown that Rho/ROCK converts mechanical stimulation into gene expression changes through the actin-myocardin-related transcription factor (MRTF)-serum response factor (SRF) pathway (Zhao et al., 2007). Dupont et al. (Dupont et al., 2011) found that stretch stimulation can activate the RhoA/ROCK signaling pathway and YAP/transcriptional co-activator with PDZ-binding motif (TAZ), promote bone formation, inhibit adipogenesis, and form actin at the same time. Similarly, RhoA feels high ECM stiffness through focal adhesion, promotes actin polymerization and stress fiber formation, transmits stiffness signals to YAP/ TAZ, and regulates the sensitivity of osteoblasts (Wagh et al., 2021). MRTF and YAP/TAZ have been confirmed as transcription factors activated by mechanical induction (FinchEdmondson and Sudol, 2016; Cai et al., 2021). The activity of ROCK is positively correlated with ECM stiffness. Although stiffness sensing is related to the regulation of multiple signal transductions, RhoA/ROCK pathway is perhaps the most prominent (Selig et al., 2020). Studies have been found that RhoA and its effector protein ROCKII regulate the differentiation of $\mathrm{C} 3 \mathrm{H} 10 \mathrm{~T} 1 / 2$ cells induced by oscillatory fluid flow to osteogenic differentiation. At the same time, activated RhoA and fluid flow have an additive effect on the expression of RUNX2 (Arnsdorf et al., 2009). Gardinier et al. (Gardinier et al., 2014) has shown that under the influence of FSS, the mechanical sensitivity of MC3T3-E1 cells is regulated by the activation of $\mathrm{P}_{2} \mathrm{Y}_{2}$ receptors through the RhoA/ROCK signal cascade under the influence of FSS. The RhoA signalling pathway is central to mechanotransduction because it plays a key role in regulating the catin cytoskeleton and its response to mechanical force.

In addition, other signaling pathways such as the transforming growth factor- $\beta$ (TGF $\beta$ )-Smad (Zou et al., 2021), NF- $\kappa B$ (Wang et al., 2015), and BMP(da Silva Madaleno et al., 2020; Wei et al., 2020), signaling pathways also have an important role in the responses of osteoblast-like cells under mechanical stimulation, and there is crosstalk between various signaling pathways (Kopf et al., 2014; Grafe et al., 2018; Shuai et al., 2018). Moreover, the effects of mechanical stimulation on the various signal pathways mediated the response of osteoblasts are interactive and related (Table 1). Once mechanical stimulus receptors are affected by mechanical loading and unloading, it is possible to activate multiple biological signaling pathways during the conversion of physical signals into chemical stimulation signals, thus generates positive or negative regulation of osteoblast cells. However, the current research is not thorough, and its mechanism needs to be further elucidated. Future research should continue to focus on clarifying the signal pathways mediating the mechanism underlying the actions of mechanical stimulation on osteoblast-like cells.

\section{CONCLUSION}

Loading and unloading mechanical stress affects the proliferation, differentiation, and function of osteoblast-like cells. Studies have shown that osteoblast-like cells, which are sensitive to mechanical stimulation, are the basic cell model for studying the processes of bone growth, development, and formation (Siddiqui and Partridge, 2016; Thomas and Jaganathan, 2021). The perception of mechanical stress by osteoblasts first involves actions on target genes through various pathways such as $\mathrm{Ca}^{2+}$, Piezo1, ECM-integrin-cytoskeleton, and cell regulatory factors. Mechanoreceptor also regulates the expression of corresponding genes to convert mechanical stimulus signals to chemical stimuli, and then regulates various receptors on the cell membrane, cytoplasm, and nucleus through chemoreceptors to regulate the bone formation mechanism (Steward and Kelly, 2015; Augat et al., 2021). (Figure 1).

Mechanical stimulation is an important regulatory factor for bone growth, reconstruction, and metabolism. Number experimental studies have investigated osteogenic effects under mechanical stress (Chermside-Scabbo et al., 2020; Eichholz et al., 2020; Jeon et al., 2021; Lei et al., 2021). The influence of different mechanical forces on bone tissue produces various effects. Analyzing the mechanism mediating the effects of mechanical 
TABLE 1 | Signal Pathways Mediating Effects of Mechanical Stress Stimulation on Osteoblast like cells. FSS, fluid shear stress; OPG: osteoprotegerin; DKK, Dickkopfrelated protein; RUNX2, Runt-related transcription factor 2; ERK, Extracellular-regulated protein kinase; BMP, Bone Morphogenetic Protein; ALP, alkaline phosphatase; NF-кB, nuclear factor kappa-B; VEGFA, vascular endothelial growth factor-A; YAP, Yes-associated protein; OCN, osteocalcin; ECM, extracellular matrix; COX-2, cyclooxygenase; (MC3T3-E1) cells, mouse embryo osteoblast precursor; TAZ, transcriptional co-activator with PDZ-binding motif; ROCK, Rho associated protein kinase.

\begin{tabular}{|c|c|c|c|c|}
\hline Stimulus type & Pathways & Mechanism & Effect & Reference \\
\hline $\begin{array}{l}\text { Axial compression } \\
\text { Hypergravity }\end{array}$ & $\begin{array}{l}\text { Activating Wnt } \\
\text { signaling }\end{array}$ & $\begin{array}{l}\text { Inhibiting the expression of DKK1 } \\
\text { Inhibiting the expression of DDK2/enhancing the } \\
\text { phosphorylation of } \beta \text {-catenin }\end{array}$ & $\begin{array}{l}\text { Upregulating the expression of OPG } \\
\text { Upregulating RUNX2/osterix/ALP/ } \\
\text { osteocalcin/ALP }\end{array}$ & $\begin{array}{l}\text { Holguin et al. (2016) } \\
\text { Kawao et al. (2020) }\end{array}$ \\
\hline Stretch stress & $\begin{array}{l}\text { Activating Notch } \\
\text { Signaling Pathway }\end{array}$ & Activating the expression of Piezo1 & $\begin{array}{l}\text { Upregulating ALP/RUNX2/OCN/BSP/ } \\
\text { promoting the osteogenic differentiation }\end{array}$ & Wang et al. (2020a) \\
\hline Cyclic stretch & & Upregulating the expression of Notch1/Notch2 & $\begin{array}{l}\text { Upregulating the expression of RUNX2/ } \\
\text { PTGS2/FOS }\end{array}$ & Ziouti et al. (2019) \\
\hline FSS & $\begin{array}{l}\text { Activating ERK } \\
\text { signaling pathway }\end{array}$ & $\begin{array}{l}\text { Upregulating the expression of COX-2/cyclin E1, } \\
\text { inhibiting caspase-3 }\end{array}$ & $\begin{array}{l}\text { Promoting the proliferation of MC3T3-E1 } \\
\text { cells }\end{array}$ & \\
\hline FSS & & $\begin{array}{l}\text { Downregulating the expression of miR-140-5p/ } \\
\text { KLF4, upregulating the expression of VEGFA }\end{array}$ & $\begin{array}{l}\text { Promoting the proliferation of MC3T3-E1 } \\
\text { cells }\end{array}$ & $\begin{array}{l}\text { Wang et al. (2021d), } \\
\text { Bin et al. (2016) }\end{array}$ \\
\hline $\begin{array}{l}\text { Stretch } \\
\text { stimulation }\end{array}$ & $\begin{array}{l}\text { Activating RhoA } \\
\text { signaling pathway }\end{array}$ & Upregulating the expression of YAP/TAZ & Promoting the osteogenic differentiation & Dupont et al. (2011) \\
\hline $\begin{array}{l}\text { High ECM } \\
\text { stiffness }\end{array}$ & & Upregulating the expression of YAP/TAZ & Triggering F-actin polymerization & Wagh et al. (2021) \\
\hline $\begin{array}{l}\text { oscillatory } \\
\text { fluid flow }\end{array}$ & & Activating ROCKII & Upregulating the expression of RUNX2 & Arnsdorf et al. (2009) \\
\hline FSS & & Activating ROCK & $\begin{array}{l}\text { Opening up of mechano- and voltage- } \\
\text { sensitive calcium channels }\end{array}$ & Gardinier et al. (2014) \\
\hline $\begin{array}{l}\text { Mechanical tensile } \\
\text { strain }\end{array}$ & $\begin{array}{l}\text { Activating NF-kB } \\
\text { signaling pathway }\end{array}$ & Upregulating the expression of BMP-2/BMP-4 & Upregulating the expression of ALP/OCN & Wang et al. (2015) \\
\hline
\end{tabular}

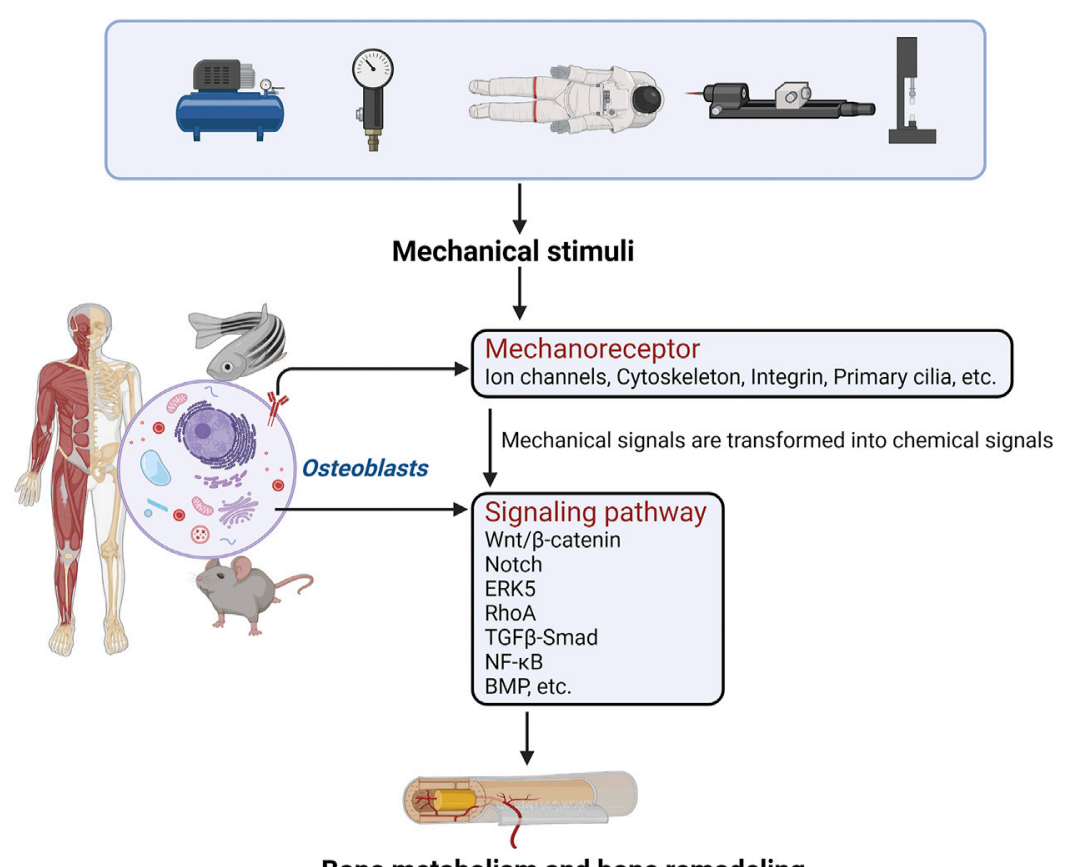

Bone metabolism and bone remodeling

FIGURE 1 | The perception of mechanical stress by osteoblasts first involves actions on mechanoreceptors through various pathways. Mechanoreceptors also regulate the expression of corresponding genes to convert mechanical stimulus signals into chemical stimuli, and regulate the relevant signal transduction pathways. Finally, bone metabolism and bone formation are regulated. 
stimulation on the regulation and metabolism of cell signaling pathways such as those of BMSCs, osteoblasts, osteoclasts, and osteocytes is currently a challenging research hotspot. Most previous studies used a single mechanical stimulus on a single mechanosensitive cell, and the mechanical loading methods and mechanical devices used did not have a relatively unified standard.

The results obtained from studies using randomly selected or combinations of different mechanical stimuli were no systematic and lacked standardization and accuracy. Consequently, designs of bone metabolism studies need to include a more suitable mechanical experimental environment to accurately control the mechanical parameters of mechanical stress stimulation, such as the type, duration, intensity, and cycle of mechanical stimulation). Furthermore, such studies should explore the influence of the body on mechanical stimulation. It is gratifying that mechanism-driven biology and biochemistry have been put into mathematical systems biology formats, this will certainly lead the research field to a more precise direction (Pastrama et al., 2018; Lavaill et al., 2020; Larcher and Scheiner, 2021).

This would provide an important theoretical basis for clinical treatment of bone diseases with a focus on issues such as bone health, fracture healing, and bone ingrowth at the bone-material interface. Further in vivo experiments need to study the changes in macroscopic bone tissue metabolic activity under stress stimulation, whereas future in vitro experiments should explore the specific mechanisms and signal transduction pathways

\section{REFERENCES}

Aisha, M. D., Nor-Ashikin, M. N. K., Sharaniza, A. B. R., Nawawi, H., and Froemming, G. R. A. (2015). Orbital Fluid Shear Stress Promotes Osteoblast Metabolism, Proliferation and Alkaline Phosphates Activity In Vitro. Exp. Cel Res. 337 (1), 87-93. doi:10.1016/j.yexcr.2015.07.002

Andersson, E. R., Sandberg, R., and Lendahl, U. (2011). Notch Signaling: Simplicity in Design, Versatility in Function. Development 138 (17), 3593-3612. doi:10. 1242/dev.063610

Arnsdorf, E. J., Tummala, P., Kwon, R. Y., and Jacobs, C. R. (2009). Mechanically Induced Osteogenic Differentiation - the Role of RhoA, ROCKII and Cytoskeletal Dynamics. J. Cel Sci 122 (Pt 4), 546-553. doi:10.1242/jcs.036293

Augat, P., Hollensteiner, M., and von Rüden, C. (2021). The Role of Mechanical Stimulation in the Enhancement of Bone Healing. Injury 52 (Suppl. 2), S78-S83. doi:10.1016/j.injury.2020.10.009

Berg, H. E., Eiken, O., Miklavcic, L., and Mekjavic, I. B. (2007). Hip, Thigh and Calf Muscle Atrophy and Bone Loss after 5-week Bedrest Inactivity. Eur. J. Appl. Physiol. 99 (3), 283-289. doi:10.1007/s00421-006-0346-y

Bin, G., Bo, Z., Jing, W., Jin, J., Xiaoyi, T., Cong, C., et al. (2016). Fluid Shear Stress Suppresses TNF- $\alpha$-Induced Apoptosis in MC3T3-E1 Cells: Involvement of ERK5-AKT-FoxO3a-Bim/FasL Signaling Pathways. Exp. Cel Res. 343 (2), 208-217. doi:10.1016/j.yexcr.2016.03.014

Bo, Z., Bin, G., Jing, W., Cuifang, W., Liping, A., Jinglin, M., et al. (2016). Fluid Shear Stress Promotes Osteoblast Proliferation via the G $\alpha$-ERK5 Signaling Pathway. Connect. Tissue Res. 57 (4), 299-306. doi:10.1080/03008207.2016.1181063

Bonewald, L. F., and Johnson, M. L. (2008). Osteocytes, Mechanosensing and Wnt Signaling. Bone 42 (4), 606-615. doi:10.1016/j.bone.2007.12.224

Bonnefoy, J., Ghislin, S., Beyrend, J., Coste, F., Calcagno, G., Lartaud, I., et al. (2021). Gravitational Experimental Platform for Animal Models, a New Platform at ESA's Terrestrial Facilities to Study the Effects of Micro- and Hypergravity on Aquatic and Rodent Animal Models. Int. J. Mol. Sci. 22 (6), 2961. doi:10.3390/ijms22062961 mediating the effects of different mechanical stimuli on various mechanosensitive cells of bone tissue. These results could be used as a foundation for future orthopedics, stomatology, and tissue engineering research studies to advance the development of this discipline.

\section{AUTHOR CONTRIBUTIONS}

All authors listed have made a substantial, direct and intellectual contribution to the work, and approved it for publication.

\section{FUNDING}

This work was funded by the National Natural Science Foundation of China (82073539 and 81773432), the Foundation of The First Affiliated Hospital of Chengdu Medical College (CYFY-GQ35), the Project of Sichuan Provincial Department of Science and Technology (22MZGC0226) and the Foundation of Chengdu Medical College (CYZYB21-12).

\section{ACKNOWLEDGMENTS}

Figure created with Biorender.com.

Bonucci, E. (2009). The Osteocyte: The Underestimated Conductor of the Bone Orchestra. Rend. Fis. Acc. Lincei 20 (3), 237-254. doi:10.1007/s12210-0090051-y

Brand, R. A. (2010). Biographical Sketch: Julius Wolff, 1836-1902. Clin. Orthop. Relat. Res. 468 (4), 1047-1049. doi:10.1007/s11999-010-1258-Z

Cai, X., Wang, K.-C., and Meng, Z. (2021). Mechanoregulation of YAP and TAZ in Cellular Homeostasis and Disease Progression. Front. Cel Dev. Biol. 9, 673599. doi: $10.3389 /$ fcell.2021.673599

Canalis, E., Parker, K., Feng, J. Q., and Zanotti, S. (2013). Osteoblast LineageSpecific Effects of Notch Activation in the Skeleton. Endocrinology 154 (2), 623-634. doi:10.1210/en.2012-1732

Cao, Z., Zhang, Y., Wei, S., Zhang, X., Guo, Y., and Han, B. (2021). Comprehensive circRNA Expression Profile and Function Network in Osteoblast-Like Cells under Simulated Microgravity. Gene 764, 145106. doi:10.1016/j.gene.2020. 145106

Chatani, M., Morimoto, H., Takeyama, K., Mantoku, A., Tanigawa, N., Kubota, K., et al. (2016). Acute Transcriptional Up-Regulation Specific to Osteoblasts/ Osteoclasts in Medaka Fish Immediately after Exposure to Microgravity. Sci. Rep. 6, 39545. doi:10.1038/srep39545

Chen, X., Liu, Y., Ding, W., Shi, J., Li, S., Liu, Y., et al. (2018). Mechanical StretchInduced Osteogenic Differentiation of Human Jaw Bone Marrow Mesenchymal Stem Cells (hJBMMSCs) via Inhibition of the NF-Kb Pathway. Cell Death Dis 9 (2), 207. doi:10.1038/s41419-018-0279-5

Chen, C. S. (2008). Mechanotransduction - a Field Pulling Together? J. Cel Sci 121 (Pt 20), 3285-3292. doi:10.1242/jcs.023507

Chermside-Scabbo, C. J., Harris, T. L., Brodt, M. D., Braenne, I., Zhang, B., Farber, C. R., et al. (2020). Old Mice Have Less Transcriptional Activation but Similar Periosteal Cell Proliferation Compared to Young-Adult Mice in Response to In Vivo Mechanical Loading. J. Bone Miner Res. 35 (9), 1751-1764. doi:10.1002/ jbmr.4031

Choi, R. B., and Robling, A. G. (2021). The Wnt Pathway: An Important Control Mechanism in Bone's Response to Mechanical Loading. Bone 153, 116087. doi:10.1016/j.bone.2021.116087 
da Silva Madaleno, C., Jatzlau, J., and Knaus, P. (2020). BMP Signalling in a Mechanical Context - Implications for Bone Biology. Bone 137, 115416. doi:10. 1016/j.bone.2020.115416

Davidson, E. H., Sultan, S. M., Butala, P., Knobel, D., and Warren, S. M. (2013). Lacunocanalicular Fluid Flow Transduces Mechanical Tension Stress during Distraction Osteogenesis. J. Craniofac. Surg. 24 (5), 1558-1564. doi:10.1097/ SCS.0b013e31828f2060

Ding, N., Geng, B., Li, Z., Yang, Q., Yan, L., Wan, L., et al. (2019). Fluid Shear Stress Promotes Osteoblast Proliferation through the NFATc1-ERK5 Pathway. Connect. Tissue Res. 60 (2), 107-116. doi:10.1080/03008207.2018.1459588

Dong, L., Song, Y., Zhang, Y., Zhao, W., Wang, C., Lin, H., et al. (2021). Mechanical Stretch Induces Osteogenesis through the Alternative Activation of Macrophages. J. Cel Physiol 236 (9), 6376-6390. doi:10. $1002 /$ jcp. 30312

Du, J., Yang, J., He, Z., Cui, J., Yang, Y., Xu, M., et al. (2020). Osteoblast and Osteoclast Activity Affect Bone Remodeling upon Regulation by Mechanical Loading-Induced Leukemia Inhibitory Factor Expression in Osteocytes. Front. Mol. Biosci. 7, 585056. doi:10.3389/fmolb.2020.585056

Duan, P., and Bonewald, L. F. (2016). The Role of the Wnt/ $\beta$-Catenin Signaling Pathway in Formation and Maintenance of Bone and Teeth. Int. J. Biochem. Cel Biol. 77 (Pt A), 23-29. doi:10.1016/j.biocel.2016.05.015

Duncan, R. L., and Turner, C. H. (1995). Mechanotransduction and the Functional Response of Bone to Mechanical Strain. Calcif Tissue Int. 57 (5), 344-358. doi:10.1007/BF00302070

Dupont, S., Morsut, L., Aragona, M., Enzo, E., Giulitti, S., Cordenonsi, M., et al. (2011). Role of YAP/TAZ in Mechanotransduction. Nature 474 (7350), 179-183. doi:10.1038/nature10137

Ei Hsu Hlaing, E., Ishihara, Y., Odagaki, N., Wang, Z., Ikegame, M., and Kamioka, H. (2020). The Expression and Regulation of Wnt1 in Tooth MovementInitiated Mechanotransduction. Am. J. Orthod. Dentofacial Orthopedics 158 (6), e151-e160. doi:10.1016/j.ajodo.2020.08.006

Eichholz, K. F., Woods, I., Riffault, M., Johnson, G. P., Corrigan, M., Lowry, M. C., et al. (2020). Human Bone Marrow Stem/Stromal Cell Osteogenesis Is Regulated via Mechanically Activated Osteocyte-Derived Extracellular Vesicles. Stem Cell Transl Med 9 (11), 1431-1447. doi:10.1002/sctm.190405

Estermann, S.-J., and Scheiner, S. (2018). Multiscale Modeling Provides Differentiated Insights to Fluid Flow-Driven Stimulation of Bone Cellular Activities. Front. Phys. 6, 76. doi:10.3389/fphy.2018.00076

Fey, D., Croucher, D. R., Kolch, W., and Kholodenko, B. N. (2012). Crosstalk and Signaling Switches in Mitogen-Activated Protein Kinase Cascades. Front. Physio. 3, 355. doi:10.3389/fphys.2012.00355

Finch-Edmondson, M., and Sudol, M. (2016). Framework to Function: Mechanosensitive Regulators of Gene Transcription. Cell Mol Biol Lett 21, 28. doi:10.1186/s11658-016-0028-7

Fu, J., Liu, X., Tan, L., Cui, Z., Liang, Y., Li, Z., et al. (2020). Modulation of the Mechanosensing of Mesenchymal Stem Cells by Laser-Induced Patterning for the Acceleration of Tissue Reconstruction through the Wnt/ $\beta$-Catenin Signaling Pathway Activation. Acta Biomater. 101, 152-167. doi:10.1016/j. actbio.2019.10.041

Gardinier, J., Yang, W., Madden, G. R., Kronbergs, A., Gangadharan, V., Adams, E., et al. (2014). P2Y2 Receptors Regulate Osteoblast Mechanosensitivity during Fluid Flow. Am. J. Physiology-Cell Physiol. 306 (11), C1058-C1067. doi:10.1152/ ajpcell.00254.2013

Globus, R. K., and Morey-Holton, E. (20161985). Hindlimb Unloading: Rodent Analog for Microgravity. J. Appl. Physiol. 120 (10), 1196-1206. doi:10.1152/ japplphysiol.00997.2015

Grafe, I., Alexander, S., Peterson, J. R., Snider, T. N., Levi, B., Lee, B., et al. (2018). TGF- $\beta$ Family Signaling in Mesenchymal Differentiation. Cold Spring Harb Perspect. Biol. 10 (5), a022202. doi:10.1101/cshperspect.a022202

$\mathrm{Gu}$, Y., and $\mathrm{Gu}$, C. (2014). Physiological and Pathological Functions of Mechanosensitive Ion Channels. Mol. Neurobiol. 50 (2), 339-347. doi:10. 1007/s12035-014-8654-4

Hardy, E., and Fernandez-Patron, C. (2020). Destroy to Rebuild: The Connection between Bone Tissue Remodeling and Matrix Metalloproteinases. Front. Physiol. 11, 47. doi:10.3389/fphys.2020.00047

Ho, M.-L., Tsai, T.-N., Chang, J.-K., Shao, T.-S., Jeng, Y.-R., and Hsu, C. (2005). Down-Regulation of N-Methyl D-Aspartate Receptor in Rat-Modeled Disuse
Osteopenia. Osteoporos. Int. 16 (12), 1780-1788. doi:10.1007/s00198-0051928-y

Hoey, D. A., Chen, J. C., and Jacobs, C. R. (2012). The Primary Cilium as a Novel Extracellular Sensor in Bone. Front. Endocrin. 3, 75. doi:10.3389/fendo.2012.00075

Hoffman, B. D., Grashoff, C., and Schwartz, M. A. (2011). Dynamic Molecular Processes Mediate Cellular Mechanotransduction. Nature 475 (7356), 316-323. doi:10.1038/nature10316

Holguin, N., Brodt, M. D., and Silva, M. J. (2016). Activation of Wnt Signaling by Mechanical Loading Is Impaired in the Bone of Old Mice. J. Bone Miner Res. 31 (12), 2215-2226. doi:10.1002/jbmr.2900

Ilizarov, G. A. (1989). The Tension-Stress Effect on the Genesis and Growth of Tissues. Part I. The Influence of Stability of Fixation and Soft-Tissue Preservation. Clin. Orthopaedics Relat. Res. 238, 249-281. doi:10.1097/ 00003086-198901000-00038

Imamura, K., Ozawa, H., Hiraide, T., Shibasaki, Y., Fukuhara, T., Takahashi, N., et al. (1990). Continuously Applied Compressive Pressure Induces Bone Resorption by a Mechanism Involving Prostaglandin E2 Synthesis. J. Cel. Physiol. 144 (2), 222-228. doi:10.1002/jcp.1041440207

Iordachescu, A., Hughes, E. A. B., Joseph, S., Hill, E. J., Grover, L. M., and Metcalfe, A. D. (2021). Trabecular Bone Organoids: A Micron-Scale 'Humanised' Prototype Designed to Study the Effects of Microgravity and Degeneration. NPJ Microgravity 7 (1), 17. doi:10.1038/s41526-021-00146-8

Iura, A., McNerny, E. G., Zhang, Y., Kamiya, N., Tantillo, M., Lynch, M., et al. (2015). Mechanical Loading Synergistically Increases Trabecular Bone Volume and Improves Mechanical Properties in the Mouse when BMP Signaling Is Specifically Ablated in Osteoblasts. PLoS One 10 (10), e0141345. doi:10.1371/ journal.pone. 0141345

Iwaniec, U. T., Wronski, T. J., Liu, J., Rivera, M. F., Arzaga, R. R., Hansen, G., et al. (2007). PTH Stimulates Bone Formation in Mice Deficient in Lrp5. J. Bone Miner Res. 22 (3), 394-402. doi:10.1359/jbmr.061118

Javaheri, B., Stern, A. R., Lara, N., Dallas, M., Zhao, H., Liu, Y., et al. (2014). Deletion of a Single $\beta$-Catenin Allele in Osteocytes Abolishes the Bone Anabolic Response to Loading. J. Bone Miner Res. 29 (3), 705-715. doi:10.1002/jbmr.2064

Jeon, H. H., Teixeira, H., and Tsai, A. (2021). Mechanistic Insight into Orthodontic Tooth Movement Based on Animal Studies: A Critical Review. J. Clin. Med. 10 (8), 1733. doi:10.3390/jcm10081733

Jiang, J., Zhao, L.-G., Teng, Y.-J., Chen, S.-L., An, L.-P., Ma, J.-L., et al. (2015). ERK5 Signalling Pathway Is Essential for Fluid Shear Stress-Induced COX-2 Gene Expression in MC3T3-E1 Osteoblast. Mol. Cel Biochem 406 (1-2), 237-243. doi:10.1007/s11010-015-2441-z

Jin, J., Jaspers, R. T., Wu, G., Korfage, J. A. M., Klein-Nulend, J., and Bakker, A. D. (2020). Shear Stress Modulates Osteoblast Cell and Nucleus Morphology and Volume. Int. J. Mol. Sci. 21 (21), 8361. doi:10.3390/ijms21218361

Jing, D., Luo, E., Cai, J., Tong, S., Zhai, M., Shen, G., et al. (2016). Mechanical Vibration Mitigates the Decrease of Bone Quantity and Bone Quality of Leptin Receptor-Deficient $\mathrm{Db} / \mathrm{Db}$ Mice by Promoting Bone Formation and Inhibiting Bone Resorption. J. Bone Miner Res. 31 (9), 1713-1724. doi:10.1002/jbmr.2837

Johnson, D. L., McAllister, T. N., and Frangos, J. A. (1996). Fluid Flow Stimulates Rapid and Continuous Release of Nitric Oxide in Osteoblasts. Am. J. Physiology-Endocrinology Metab. 271 (1 Pt 1), E205-E208. doi:10.1152/ ajpendo.1996.271.1.E205

Kameyama, S., Yoshimura, Y., Kameyama, T., Kikuiri, T., Matsuno, M., Deyama, Y., et al. (2013). Short-Term Mechanical Stress Inhibits Osteoclastogenesis via Suppression of DC-STAMP in RAW264.7 Cells. Int. J. Mol. Med. 31 (2), 292-298. doi:10.3892/ijmm.2012.1220

Kaneko-Kawano, T., and Suzuki, K. (2015). Mechanical Stress Regulates Gene Expression via Rho/Rho-Kinase Signaling Pathway. J. Phys. Fitness Sports Med. 4 (1), 53-61. doi:10.7600/jpfsm.4.53

Kang, K. S., Hong, J. M., and Robling, A. G. (2016). Postnatal $\beta$-Catenin Deletion from Dmp1-Expressing Osteocytes/osteoblasts Reduces Structural Adaptation to Loading, but Not Periosteal Load-Induced Bone Formation. Bone 88, 138-145. doi:10.1016/j.bone.2016.04.028

Kani, K. K., Porrino, J. A., and Chew, F. S. (2020). External Fixators: Looking Beyond the Hardware Maze. Skeletal Radiol. 49 (3), 359-374. doi:10.1007/ s00256-019-03306-w

Kawao, N., Morita, H., Iemura, S., Ishida, M., and Kaji, H. (2020). Roles of Dkk2 in the Linkage from Muscle to Bone during Mechanical Unloading in Mice. Int. J. Mol. Sci. 21 (7), 2547. doi:10.3390/ijms21072547 
Kefauver, J. M., Ward, A. B., and Patapoutian, A. (2020). Discoveries in Structure and Physiology of Mechanically Activated Ion Channels. Nature 587 (7835), 567-576. doi:10.1038/s41586-020-2933-1

Kiel, D. P., Ferrari, S. L., Cupples, L. A., Karasik, D., Manen, D., Imamovic, A., et al. (2007). Genetic Variation at the Low-Density Lipoprotein Receptor-Related Protein 5 (LRP5) Locus Modulates Wnt Signaling and the Relationship of Physical Activity with Bone mineral Density in Men. Bone 40 (3), 587-596. doi:10.1016/j.bone.2006.09.029

Klein-Nulend, J., Burger, E. H., Semeins, C. M., Raisz, L. G., and Pilbeam, C. C. (1997). Pulsating Fluid Flow Stimulates Prostaglandin Release and Inducible Prostaglandin G/H Synthase mRNA Expression in Primary Mouse Bone Cells. J. Bone Miner Res. 12 (1), 45-51. doi:10.1359/jbmr.1997.12.1.45

Kong, L., Wang, B., Yang, X., He, B., Hao, D., and Yan, L. (2020). IntegrinAssociated Molecules and Signalling Cross Talking in Osteoclast Cytoskeleton Regulation. J. Cel Mol Med 24 (6), 3271-3281. doi:10.1111/ jcmm. 15052

Kopf, J., Paarmann, P., Hiepen, C., Horbelt, D., and Knaus, P. (2014). BMP Growth Factor Signaling in a Biomechanical Context. Biofactors 40 (2), 171-187. doi:10. 1002/biof.1137

Kounakis, K., and Tavernarakis, N. (2019). The Cytoskeleton as a Modulator of Aging and Neurodegeneration. Adv. Exp. Med. Biol. 1178, 227-245. doi:10. 1007/978-3-030-25650-0_12

Kumar, R., Tiwari, A. K., Tripathi, D., Main, R. P., Kumar, N., Sihota, P., et al. (2021). Anatomical Variations in Cortical Bone Surface Permeability: Tibia Versus Femur. J. Mech. Behav. Biomed. Mater. 113, 104122. doi:10.1016/j. jmbbm.2020.104122

Lacey, D. C., Simmons, P. J., Graves, S. E., and Hamilton, J. A. (2009). Proinflammatory Cytokines Inhibit Osteogenic Differentiation from Stem Cells: Implications for Bone Repair during Inflammation. Osteoarthritis and Cartilage 17 (6), 735-742. doi:10.1016/j.joca.2008.11.011

Larcher, I., and Scheiner, S. (2021). Parameter Reduction, Sensitivity Studies, and Correlation Analyses Applied to a Mechanobiologically Regulated Bone Cell Population Model of the Bone Metabolism. Comput. Biol. Med. 136, 104717. doi:10.1016/j.compbiomed.2021.104717

Lavaill, M., Trichilo, S., Scheiner, S., Forwood, M. R., Cooper, D. M. L., and Pivonka, P. (2020). Study of the Combined Effects of PTH Treatment and Mechanical Loading in Postmenopausal Osteoporosis Using a New Mechanistic PK-PD Model. Biomech. Model. Mechanobiol 19 (5), 1765-1780. doi:10.1007/s10237-020-01307-6

Lei, X., Liu, Q., Li, S., Zhang, Z., and Yang, X. (2021). Effects of Fluid Shear Stress on Expression of Focal Adhesion Kinase in MG-63 Human Osteoblast-like Cells on Different Surface Modification of Titanium. Bioengineered 12 (1), 4962-4971. doi:10.1080/21655979.2021.1962686

Li, P., Ma, Y. C., Shen, H. L., Han, H., Wang, J., Cheng, H. J., et al. (2012). Cytoskeletal Reorganization Mediates Fluid Shear Stress-Induced ERK5 Activation in Osteoblastic Cells. Cell. Biol. Int. 36 (3), 229-236. doi:10.1042/ CBI20110113

Li, X., Han, L., Nookaew, I., Mannen, E., Silva, M. J., Almeida, M., et al. (2019). Stimulation of Piezo1 by Mechanical Signals Promotes Bone Anabolism. Elife 8, e49631. doi:10.7554/eLife.49631

Li, W., Zhao, J., Sun, W., Wang, H., Pan, Y., Wang, L., et al. (2020a). Osteocytes Promote Osteoclastogenesis via Autophagy-Mediated RANKL Secretion under Mechanical Compressive Force. Arch. Biochem. Biophys. 694, 108594. doi:10. 1016/j.abb.2020.108594

Li, Z., Zheng, J., Wan, D., and Yang, X. (2020b). Uniaxial Static Strain Promotes Osteoblast Proliferation and Bone Matrix Formation in Distraction Osteogenesis In Vitro. Biomed. Res. Int. 2020, 3906426. doi:10.1155/2020/ 3906426

Li, Y., Ling, J., and Jiang, Q. (2021). Inflammasomes in Alveolar Bone Loss. Front. Immunol. 12, 691013. doi:10.3389/fimmu.2021.691013

Luo, H., Wu, H., Tan, X., Ye, Y., Huang, L., Dai, H., et al. (2021). Osteopenic Effects of High-Fat Diet-Induced Obesity on Mechanically Induced Alveolar Bone Remodeling. Oral Dis. 27 (5), 1243-1256. doi:10.1111/odi.13651

Malone, A. M. D., Anderson, C. T., Tummala, P., Kwon, R. Y., Johnston, T. R., Stearns, T., et al. (2007). Primary Cilia Mediate Mechanosensing in Bone Cells by a Calcium-Independent Mechanism. Proc. Natl. Acad. Sci. 104 (33), 13325-13330. doi:10.1073/pnas.0700636104
Manolagas, S. C. (2010). From Estrogen-Centric to Aging and Oxidative Stress: a Revised Perspective of the Pathogenesis of Osteoporosis. Endocr. Rev. 31 (3), 266-300. doi:10.1210/er.2009-0024

Michael, M., and Parsons, M. (2020). New Perspectives on Integrin-Dependent Adhesions. Curr. Opin. Cel Biol. 63, 31-37. doi:10.1016/j.ceb.2019.12.008

Miwa, M., Kozawa, O., Tokuda, H., Kawakubo, A., Yoneda, M., Oiso, Y., et al. (1991). Effects of Hypergravity on Proliferation and Differentiation of Osteoblast-Like Cells. Bone Mineral. 14 (1), 15-25. doi:10.1016/01696009(91)90099-1

Nakajima, T. (1991). Effects of Hypergravity on Migration, Proliferation and Function of Mouse Osteoblastic Cell Line MC3T3-E1. J. Stomatol.Soc.,Jpn. 58 (2), 529-544. doi:10.5357/koubyou.58.529

Nomura, S., and Takano-Yamamoto, T. (2000). Molecular Events Caused by Mechanical Stress in Bone. Matrix Biol. 19 (2), 91-96. doi:10.1016/s0945053x(00)00050-0

Norwitz, N. G., Mota, A. S., Misra, M., and Ackerman, K. E. (2019). LRP5, Bone Density, and Mechanical Stress: A Case Report and Literature Review. Front. Endocrinol. 10, 184. doi:10.3389/fendo.2019.00184

Owen, R., and Reilly, G. C. (2018). In Vitro Models of Bone Remodelling and Associated Disorders. Front. Bioeng. Biotechnol. 6, 134. doi:10.3389/fbioe.2018. 00134

Ozawa, H., Imamura, K., Abe, E., Takahashi, N., Hiraide, T., Shibasaki, Y., et al. (1990). Effect of a Continuously Applied Compressive Pressure on Mouse Osteoblast-Like Cells (MC3T3-E1) In Vitro. J. Cel. Physiol. 142 (1), 177-185. doi:10.1002/jcp.1041420122

Parandakh, A., Tafazzoli-Shadpour, M., and Khani, M.-M. (2017). Stepwise Morphological Changes and Cytoskeletal Reorganization of Human Mesenchymal Stem Cells Treated by Short-Time Cyclic Uniaxial Stretch. In Vitro Cell.Dev.Biol.-Animal 53 (6), 547-553. doi:10.1007/s11626-017-0131-8

Pastrama, M.-I., Scheiner, S., Pivonka, P., and Hellmich, C. (2018). A Mathematical Multiscale Model of Bone Remodeling, Accounting for Pore Space-Specific Mechanosensation. Bone 107, 208-221. doi:10.1016/j.bone.2017.11.009

Pavalko, F. M., Gerard, R. L., Ponik, S. M., Gallagher, P. J., Jin, Y., and Norvell, S. M. (2003). Fluid Shear Stress Inhibits TNF- $\alpha$-Induced Apoptosis in Osteoblasts: A Role for Fluid Shear Stress-Induced Activation of PI3-Kinase and Inhibition of Caspase-3. J. Cel. Physiol. 194 (2), 194-205. doi:10.1002/jcp.10221

Plotkin, L. I., Mathov, I., Aguirre, J. I., Parfitt, A. M., Manolagas, S. C., and Bellido, T. (2005). Mechanical Stimulation Prevents Osteocyte Apoptosis: Requirement of Integrins, Src Kinases, and ERKs. Am. J. Physiology-Cell Physiol. 289 (3), C633-C643. doi:10.1152/ajpcell.00278.2004

Price, C., Zhou, X., Li, W., and Wang, L. (2011). Real-time Measurement of Solute Transport within the Lacunar-Canalicular System of Mechanically Loaded Bone: Direct Evidence for Load-Induced Fluid Flow. J. Bone Miner Res. 26 (2), 277-285. doi:10.1002/jbmr.211

Prideaux, M., Findlay, D. M., and Atkins, G. J. (2016). Osteocytes: The Master Cells in Bone Remodelling. Curr. Opin. Pharmacol. 28, 24-30. doi:10.1016/j.coph. 2016.02.003

Qin, W., Liu, L., Wang, Y., Wang, Z., Yang, A., and Wang, T. (2019). Mir-494 Inhibits Osteoblast Differentiation by Regulating BMP Signaling in Simulated Microgravity. Endocrine 65 (2), 426-439. doi:10.1007/s12020-019-01952-7

Qin, L., Liu, W., Cao, H., and Xiao, G. (2020). Molecular Mechanosensors in Osteocytes. Bone Res. 8, 23. doi:10.1038/s41413-020-0099-y

Ragnarsson, K. T. (2015). Bone Loss and Fractures in Limbs Paralyzed by Spinal Cord Injury: Prevention, Diagnosis, and Treatment. J. Spinal Cord Med. 38 (1), 10-12. doi:10.1179/2045772314Y.0000000200

Ridley, A. J., and Hall, A. (1992). The Small GTP-Binding Protein Rho Regulates the Assembly of Focal Adhesions and Actin Stress Fibers in Response to Growth Factors. Cell 70 (3), 389-399. doi:10.1016/0092-8674(92)90163-7

Robling, A. G., and Turner, C. H. (2009). Mechanical Signaling for Bone Modeling and Remodeling. Crit. Rev. Eukar Gene Expr. 19 (4), 319-338. doi:10.1615/ critreveukargeneexpr.v19.i4.50

Rucci, N., Rufo, A., Alamanou, M., and Teti, A. (2007). Modeled Microgravity Stimulates Osteoclastogenesis and Bone Resorption by Increasing Osteoblast RANKL/OPG Ratio. J. Cel. Biochem. 100 (2), 464-473. doi:10.1002/jcb.21059

Rutkovskiy, A., Stensløkken, K.-O., and Vaage, I. J. (2016). Osteoblast Differentiation at a Glance. Med. Sci. Monit. Basic Res. 22, 95-106. doi:10. $12659 /$ msmbr.901142 
Sandbo, N., Smolyaninova, L. V., Orlov, S. N., and Dulin, N. O. (2016). Control of Myofibroblast Differentiation and Function by Cytoskeletal Signaling. Biochem. Mosc. 81 (13), 1698-1708. doi:10.1134/S0006297916130071

Sawakami, K., Robling, A. G., Ai, M., Pitner, N. D., Liu, D., Warden, S. J., et al. (2006). The Wnt Co-Receptor LRP5 Is Essential for Skeletal Mechanotransduction but Not for the Anabolic Bone Response to Parathyroid Hormone Treatment. J. Biol. Chem. 281 (33), 23698-23711. doi:10.1074/jbc.M601000200

Saxena, R., Pan, G., Dohm, E. D., and McDonald, J. M. (2011). Modeled Microgravity and Hindlimb Unloading Sensitize Osteoclast Precursors to RANKL-Mediated Osteoclastogenesis. J. Bone Miner Metab. 29 (1), 111-122. doi:10.1007/s00774-010-0201-4

Scheiner, S., Pivonka, P., Smith, D. W., Dunstan, C. R., and Hellmich, C. (2014). Mathematical Modeling of Postmenopausal Osteoporosis and its Treatment by the Anti-Catabolic Drug Denosumab. Int. J. Numer. Meth. Biomed. Engng. 30 (1), 1-27. doi:10.1002/cnm.2584

Scheiner, S., Pivonka, P., and Hellmich, C. (2016). Poromicromechanics Reveals that Physiological Bone Strains Induce Osteocyte-Stimulating Lacunar Pressure. Biomech. Model. Mechanobiol 15 (1), 9-28. doi:10.1007/s10237015-0704-y

Selig, M., Lauer, J. C., Hart, M. L., and Rolauffs, B. (2020). Mechanotransduction and Stiffness-Sensing: Mechanisms and Opportunities to Control Multiple Molecular Aspects of Cell Phenotype as a Design Cornerstone of CellInstructive Biomaterials for Articular Cartilage Repair. Int. J. Mol. Sci. 21 (15), 5399. doi:10.3390/ijms21155399

Selvakumarasamy, K., Poornachandra, S., and Amutha, R. (2019). K - Shrinkage Function for ECG Signal Denoising. J. Med. Syst. 43 (8), 248. doi:10.1007/ s10916-019-1375-5

Shen, X.-Q., Geng, Y.-M., Liu, P., Huang, X.-Y., Li, S.-Y., Liu, C.-D., et al. (2017). Magnitude-Dependent Response of Osteoblasts Regulated by Compressive Stress. Sci. Rep. 7, 44925. doi:10.1038/srep44925

Shi, W., Zhang, Y., Chen, K., He, J., Feng, X., Wei, W., et al. (2020). Primary Cilia Act as Microgravity Sensors by Depolymerizing Microtubules to Inhibit Osteoblastic Differentiation and Mineralization. Bone 136, 115346. doi:10. 1016/j.bone.2020.115346

Shuai, C., Yang, W., Peng, S., Gao, C., Guo, W., Lai, Y., et al. (2018). Physical Stimulations and Their Osteogenesis-Inducing Mechanisms. Int. J. Bioprint 4 (2), 138. doi:10.18063/IJB.v4i2.138

Siddiqui, J. A., and Partridge, N. C. (2016). Physiological Bone Remodeling: Systemic Regulation and Growth Factor Involvement. Physiology 31 (3), 233-245. doi:10.1152/physiol.00061.2014

Somemura, S., Kumai, T., Yatabe, K., Sasaki, C., Fujiya, H., Niki, H., et al. (2021). Physiologic Mechanical Stress Directly Induces Bone Formation by Activating Glucose Transporter 1 (Glut 1) in Osteoblasts, Inducing Signaling via NAD+Dependent Deacetylase (Sirtuin 1) and Runt-Related Transcription Factor 2 (Runx2). Int. J. Mol. Sci. 22 (16), 9070. doi:10.3390/ijms22169070

Sonam, S., Sathe, S. R., Yim, E. K. F., Sheetz, M. P., and Lim, C. T. (2016). Cell Contractility Arising from Topography and Shear Flow Determines Human Mesenchymal Stem Cell Fate. Sci. Rep. 6, 20415. doi:10.1038/srep20415

Song, J., Liu, L., Lv, L., Hu, S., Tariq, A., Wang, W., et al. (2020). Fluid Shear Stress Induces Runx-2 Expression via Upregulation of PIEZO1 in MC3T3-E1 Cells. Cell Biol Int 44 (7), 1491-1502. doi:10.1002/cbin.11344

Stein, T. P. (2013). Weight, Muscle and Bone Loss during Space Flight: Another Perspective. Eur. J. Appl. Physiol. 113 (9), 2171-2181. doi:10.1007/s00421-0122548-9

Steinbuck, M. P., and Winandy, S. (2018). A Review of Notch Processing with New Insights into Ligand-independent Notch Signaling in T-Cells. Front. Immunol. 9, 1230. doi:10.3389/fimmu.2018.01230

Steller, J., Alberts, J., and Ronca, A. (2018). Oxidative Stress as Cause, Consequence, or Biomarker of Altered Female Reproduction and Development in the Space Environment. Int. J. Mol. Sci. 19 (12), 3729. doi:10.3390/ijms19123729

Steward, A. J., and Kelly, D. J. (2015). Mechanical Regulation of Mesenchymal Stem Cell Differentiation. J. Anat. 227 (6), 717-731. doi:10.1111/joa.12243

Sugisawa, E., Takayama, Y., Takemura, N., Kondo, T., Hatakeyama, S., Kumagai, Y., et al. (2020). RNA Sensing by Gut Piezol Is Essential for Systemic Serotonin Synthesis. Cell 182 (3), 609-624. e621. doi:10.1016/j.cell.2020.06.022

Suniaga, S., Rolvien, T., Vom Scheidt, A., Fiedler, I. A. K., Bale, H. A., Huysseune, A., et al. (2018). Increased Mechanical Loading through Controlled Swimming
Exercise Induces Bone Formation and Mineralization in Adult Zebrafish. Sci. Rep. 8 (1), 3646. doi:10.1038/s41598-018-21776-1

Tanaka, S. M., Sun, H. B., Roeder, R. K., Burr, D. B., Turner, C. H., and Yokota, H. (2005). Osteoblast Responses One Hour after Load-Induced Fluid Flow in a Three-Dimensional Porous Matrix. Calcif Tissue Int. 76 (4), 261-271. doi:10. 1007/s00223-004-0238-2

Tapial Martínez, P., López Navajas, P., and Lietha, D. (2020). FAK Structure and Regulation by Membrane Interactions and Force in Focal Adhesions. Biomolecules 10 (2), 179. doi:10.3390/biom10020179

Thomas, S., and Jaganathan, B. G. (2021). Signaling Network Regulating Osteogenesis in Mesenchymal Stem Cells. J. Cel Commun. Signal. 16, 47-61. doi:10.1007/s12079-021-00635-1

Tripuwabhrut, P., Mustafa, M., Gjerde, C. G., Brudvik, P., and Mustafa, K. (2013). Effect of Compressive Force on Human Osteoblast-Like Cells and Bone Remodelling: an In Vitro Study. Arch. Oral Biol. 58 (7), 826-836. doi:10. 1016/j.archoralbio.2013.01.004

Uda, Y., Azab, E., Sun, N., Shi, C., and Pajevic, P. D. (2017). Osteocyte Mechanobiology. Curr. Osteoporos. Rep. 15 (4), 318-325. doi:10.1007/ s11914-017-0373-0

Uzbekov, R. E., Maurel, D. B., Aveline, P. C., Pallu, S., Benhamou, C. L., and Rochefort, G. Y. (2012). Centrosome Fine Ultrastructure of the Osteocyte Mechanosensitive Primary Cilium. Microsc. Microanal 18 (6), 1430-1441. doi:10.1017/S1431927612013281

Vogel, V., and Sheetz, M. (2006). Local Force and Geometry Sensing Regulate Cell Functions. Nat. Rev. Mol. Cel Biol 7 (4), 265-275. doi:10.1038/nrm1890

Wagh, K., Ishikawa, M., Garcia, D. A., Stavreva, D. A., Upadhyaya, A., and Hager, G. L. (2021). Mechanical Regulation of Transcription: Recent Advances. Trends Cel Biol. 31 (6), 457-472. doi:10.1016/j.tcb.2021.02.008

Wang, Q.-S., Zhang, X.-C., Li, R.-X., Sun, J.-G., Su, W.-H., Guo, Y., et al. (2015). A Comparative Study of Mechanical Strain, Icariin and Combination Stimulations on Improving Osteoinductive Potential via NF-kappaB Activation in Osteoblast-Like Cells. Biomed. Eng. Online 14, 46. doi:10.1186/ s12938-015-0039-z

Wang, Y., Wang, K., Hu, Z., Zhou, H., Zhang, L., Wang, H., et al. (2018). MicroRNA-139-3p Regulates Osteoblast Differentiation and Apoptosis by Targeting ELK1 and Interacting with Long Noncoding RNA ODSM. Cel Death Dis 9 (11), 1107. doi:10.1038/s41419-018-1153-1

Wang, L., Wang, X., Ji, N., Li, H. M., and Cai, S. X. (2020a). Mechanisms of the Mechanically Activated Ion Channel Piezol Protein in Mediating Osteogenic Differentiation of Periodontal Ligament Stem Cells via the Notch Signaling Pathway. Hua Xi Kou Qiang Yi Xue Za Zhi 38 (6), 628-636. doi:10.7518/hxkq. 2020.06.004

Wang, L., You, X., Lotinun, S., Zhang, L., Wu, N., and Zou, W. (2020b). Mechanical Sensing Protein PIEZO1 Regulates Bone Homeostasis via Osteoblast-Osteoclast Crosstalk. Nat. Commun. 11 (1), 282. doi:10.1038/ s41467-019-14146-6

Wang, Y., Wang, K., Zhang, L., Tan, Y., Hu, Z., Dang, L., et al. (2020c). Targeted Overexpression of the Long Noncoding RNA ODSM Can Regulate Osteoblast Function In Vitro and In Vivo. Cel Death Dis 11 (2), 133. doi:10.1038/s41419020-2325-3

Wang, F.-S., Wu, R.-W., Chen, Y.-S., Ko, J.-Y., Jahr, H., and Lian, W.-S. (2021a). Biophysical Modulation of the Mitochondrial Metabolism and Redox in Bone Homeostasis and Osteoporosis: How Biophysics Converts into Bioenergetics. Antioxidants 10 (9), 1394. doi:10.3390/antiox10091394

Wang, H., Dong, J., Li, G., Tan, Y., Zhao, H., Zhang, L., et al. (2021b). The Small Protein MafG Plays a Critical Role in MC3T3-E1 Cell Apoptosis Induced by Simulated Microgravity and Radiation. Biochem. Biophysical Res. Commun. 555, 175-181. doi:10.1016/j.bbrc.2021.03.133

Wang, J., Li, J., Liu, J., Lin, M., Mao, S., Wang, Y., et al. (2021c). Adsorption Force of Fibronectin: A Balance Regulator to Transmission of Cell Traction Force and Fluid Shear Stress. Biomacromolecules 22 (8), 3264-3273. doi:10.1021/acs. biomac.1c00375

Wang, X., Geng, B., Wang, H., Wang, S., Zhao, D., He, J., et al. (2021d). Fluid Shear Stress-Induced Down-Regulation of microRNA-140-5p Promotes Osteoblast Proliferation by Targeting VEGFA via the ERK5 Pathway. Connect. Tissue Res., 1-13. doi:10.1080/03008207.2021.1891228

Wang, X., He, J., Wang, H., Zhao, D., Geng, B., Wang, S., et al. (2021e). Fluid Shear Stress Regulates Osteoblast Proliferation and Apoptosis via the lncRNA TUG1/ 
miR-34a/FGFR1 Axis. J. Cel Mol Med 25 (18), 8734-8747. doi:10.1111/jcmm. 16829

Wei, Q., Holle, A., Li, J., Posa, F., Biagioni, F., Croci, O., et al. (2020). BMP-2 Signaling and Mechanotransduction Synergize to Drive Osteogenic Differentiation via YAP/TAZ. Adv. Sci. 7 (15), 1902931. doi:10.1002/advs. 201902931

Whitfield, J. F. (2003). Primary Cilium?is it an Osteocyte's Strain-Sensing Flowmeter? J. Cel. Biochem. 89 (2), 233-237. doi:10.1002/jcb.10509

Wittkowske, C., Reilly, G. C., Lacroix, D., and Perrault, C. M. (2016). In Vitro Bone Cell Models: Impact of Fluid Shear Stress on Bone Formation. Front. Bioeng. Biotechnol. 4, 87. doi:10.3389/fbioe.2016.00087

Woo, S.-H., Ranade, S., Weyer, A. D., Dubin, A. E., Baba, Y., Qiu, Z., et al. (2014). Piezo2 Is Required for Merkel-Cell Mechanotransduction. Nature 509 (7502), 622-626. doi:10.1038/nature13251

Woodcock, E. M., Girvan, P., Eckert, J., Lopez-Duarte, I., Kubánková, M., van Loon, J. J. W. A., et al. (2019). Measuring Intracellular Viscosity in Conditions of Hypergravity. Biophysical J. 116 (10), 1984-1993. doi:10.1016/j.bpj.2019. 03.038

Xiang, L.-X., Ran, Q., Chen, L., Xiang, Y., Li, F.-J., Zhang, X.-M., et al. (2020). CR6interacting Factor-1 Contributes to Osteoclastogenesis by Inducing Receptor Activator of Nuclear Factor $\mathrm{\kappa B}$ Ligand after Radiation. World J Stem Cells 12 (3), 222-240. doi:10.4252/wjsc.v12.i3.222

Xiao, Z., Zhang, S., Mahlios, J., Zhou, G., Magenheimer, B. S., Guo, D., et al. (2006). Cilia-Like Structures and Polycystin-1 in Osteoblasts/Osteocytes and Associated Abnormalities in Skeletogenesis and Runx2 Expression. J. Biol. Chem. 281 (41), 30884-30895. doi:10.1074/jbc.M604772200

Xing, Y., He, Z., Warnock, J. N., Hilbert, S. L., and Yoganathan, A. P. (2004). Effects of Constant Static Pressure on the Biological Properties of Porcine Aortic Valve Leaflets. Ann. Biomed. Eng. 32 (4), 555-562. doi:10.1023/b:abme.0000019175. $12013.8 \mathrm{f}$

Yanagisawa, M., Suzuki, N., Mitsui, N., Koyama, Y., Otsuka, K., and Shimizu, N. (2008). Compressive Force Stimulates the Expression of Osteogenesis-Related Transcription Factors in ROS 17/2.8 Cells. Arch. Oral Biol. 53 (3), 214-219. doi:10.1016/j.archoralbio.2007.08.012

Yang, J., Li, J., Cui, X., Li, W., Xue, Y., Shang, P., et al. (2020). Blocking Glucocorticoid Signaling in Osteoblasts and Osteocytes Prevents Mechanical Unloading-Induced Cortical Bone Loss. Bone 130, 115108. doi:10.1016/j.bone. 2019.115108

Yuan, X., Serra, R. A., and Yang, S. (2015). Function and Regulation of Primary Cilia and Intraflagellar Transport Proteins in the Skeleton. Ann. N.Y. Acad. Sci. 1335, 78-99. doi:10.1111/nyas.12463

Yuan, J., Dong, X., Yap, J., and Hu, J. (2020). The MAPK and AMPK Signalings: Interplay and Implication in Targeted Cancer Therapy. J. Hematol. Oncol. 13 (1), 113. doi:10.1186/s13045-020-00949-4
Zanotti, S., Smerdel-Ramoya, A., and Canalis, E. (2011). HES1 (Hairy and Enhancer of Split 1) Is a Determinant of Bone Mass. J. Biol. Chem. 286 (4), 2648-2657. doi:10.1074/jbc.M110.183038

Zhang, B., An, L., Geng, B., Ding, N., Coalson, E., Wan, L., et al. (2021). ERK5 Negatively Regulates Kruppel-Like Factor 4 and Promotes Osteogenic Lineage Cell Proliferation in Response to MEK5 Overexpression or Fluid Shear Stress. Connect. Tissue Res. 62 (2), 194-205. doi:10.1080/03008207.2019.1670650

Zhao, X.-H., Laschinger, C., Arora, P., Sza'szi, K., Kapus, A., and McCulloch, C. A. (2007). Force Activates Smooth Muscle $\alpha$-Actin Promoter Activity through the Rho Signaling Pathway. J. Cel Sci 120 (Pt 10), 1801-1809. doi:10.1242/jcs.001586

Zhou, S., Zu, Y., Sun, Z., Zhuang, F., and Yang, C. (2015). Effects of Hypergravity on Osteopontin Expression in Osteoblasts. PLoS One 10 (6), e0128846. doi:10. 1371/journal.pone.0128846

Zhou, S., Yang, X., Hu, J., Mo, C., Cao, Y., and Yang, C. (2018). Continuous Hypergravity Alters the Cytoplasmic Elasticity of MC3T3-E1 Osteoblasts via Actin Filaments. J. Biomech. 72, 222-227. doi:10.1016/j.jbiomech.2018.02.024

Zhou, T., Gao, B., Fan, Y., Liu, Y., Feng, S., Cong, Q., et al. (2020). Piezo1/2 Mediate Mechanotransduction Essential for Bone Formation through Concerted Activation of NFAT-YAP1-Ss-Catenin. Elife 9, e52779. doi:10.7554/eLife.52779

Ziouti, F., Ebert, R., Rummler, M., Krug, M., Müller-Deubert, S., Lüdemann, M., et al. (2019). NOTCH Signaling Is Activated through Mechanical Strain in Human Bone Marrow-Derived Mesenchymal Stromal Cells. Stem Cell Int. 2019, 5150634. doi:10.1155/2019/5150634

Zou, M.-L., Chen, Z.-H., Teng, Y.-Y., Liu, S.-Y., Jia, Y., Zhang, K.-W., et al. (2021). The Smad Dependent TGF- $\beta$ and BMP Signaling Pathway in Bone Remodeling and Therapies. Front. Mol. Biosci. 8, 593310. doi:10.3389/fmolb.2021.593310

Conflict of Interest: The authors declare that the research was conducted in the absence of any commercial or financial relationships that could be construed as a potential conflict of interest.

Publisher's Note: All claims expressed in this article are solely those of the authors and do not necessarily represent those of their affiliated organizations, or those of the publisher, the editors and the reviewers. Any product that may be evaluated in this article, or claim that may be made by its manufacturer, is not guaranteed or endorsed by the publisher.

Copyright $\odot 2022 \mathrm{Liu}, \mathrm{Tu}$, Wang, $\mathrm{Li}, \mathrm{Li}$, Yu and Zhang. This is an open-access article distributed under the terms of the Creative Commons Attribution License (CC BY). The use, distribution or reproduction in other forums is permitted, provided the original author(s) and the copyright owner(s) are credited and that the original publication in this journal is cited, in accordance with accepted academic practice. No use, distribution or reproduction is permitted which does not comply with these terms. 